\title{
A Model of the Civil Participation in the Context of the Specificities of the Political Space of the Russian Federation's Regions
}

Irina Aleksandrovna Batanina, ${ }^{+*}$ Anastasiya Aleksandrovna Lavrikova, ${ }^{\dagger}$ Sergey Aleksandrovich Pukhanov $^{\dagger}$ and Olga Evgenievna Shumilova ${ }^{\dagger}$

\section{Abstract}

The structure of political opportunities was the study basis for determining the type of civil subjectivity based on the parameters of political competence (awareness) of the population living in the regions of Russia. The representatives of the expert groups from Belgorod region, Moscow region, the city of Moscow, Bryansk region, Vladimir region, Voronezh region, Lipetsk region, Orel region, Ivanovo region, Ryazan region, Yaroslavl region, Kostroma region, Tambov region, Tver region, Tula region took part in the research. This study has enabled the researchers to determine the preferred model of the political participation for each type of the region in the Russian Federation.Consequently, to suggest for recommendations, which will help to synchronise the structure of the political opportunities with the parameters of constructive political participation, which will lead to increasing the consolidation of the elite and mass groups and to deradicalisation of political interactions. It was proved, that it could be methodologically justified to view the category "political participation" in connection with the category "political activity". On the basis of the main attributes of the activity, an operationalisation of the concept of "political participation" was conducted.

Taking into account that the regions of the Russian Federation even within the boundaries of one Federal District differ from each other in levels of social and economic development, "structure of political possibilities", types of the elite and mass value systems, the forms, directivity and effectiveness of the local initiatives also vary considerably. The complex research enabled the authors to verify the validity of the conclusions. The research employed a combination of qualitative and quantitative methods.

The results of the expert survey demonstrated that the specificity of any form of political participation is determined by several factors: the political context, the social context, culture, a historical process and a level of political consciousness.

Keywords: Model of the Civil Participation, Political Space, Priority-Oriented Models, The Russian Federation's Regions

\footnotetext{
${ }^{\dagger}$ Institute of Humanitarian and Social Sciences, Federal State Educational Establishment of Higher Education "Tula State University", Tula, Russia,

*Corresponding Author, Email: batanina@mail.ru

(C)2018 Batanina et al. This is an Open Access article distributed under the terms of the Creative Commons Attribution License (http://creativecommons.org/licenses/by/2.0), which permits unrestricted use, distribution, and reproduction in any medium, provided the original work is properly cited.
} 


\section{Introduction}

The model of political participation is a subject of theoretical discussions by many researchers. In particular, the following two main postulates of M. Olson's collective action theory are subjected to criticism. They are nonparticipation as an individual's rational conduct in the frame of the "free-riders dilemma" and the necessity of a formal organisation for the unification of the collective action participants. M. Barns, B. Bimber and some other scholars have concluded that the general accessibility of modern news and communication media reduces costs and enhances profit from the successful collective action. This leads to a change in rational individual's behaviour: a potential participant in collective action possesses greater possibilities than before to make a rational choice concerning his/her participation (in this regard, the "free-rider" variant is only one of many possible variants). The flexible network structures are predominant, and they are "more effective in the modern complex social context" than traditional hierarchical structures.

The citizen's attitude towards the forms and mechanisms of mass media usage (news, social networks, etc.) is an essential factor, defining the model of citizens' political participation, according to the works by modern political scientists and sociologists. For example, the study conducted in 2015 (Hong Kong) shows the role of using mass media in the development of political beliefs. The degree of influence on political participation depends on the citizen's interest in the news (Wang, Shen, 2018). The researchers at the University of Michigan (USA) explore the characteristics of a form of social and political participation of young people based on the exchange of video content, "[r]esults show that publicly (as compared to anonymously) sharing a selected video on one's own Facebook wall led to a greater willingness to volunteer for an issuerelated cause. Participants' existing use of social media for engagement in social issues/causes moderated the effect, such that only participants low in use of social media for social engagement were susceptible to the sharing manipulation" (Lane, Dal Cin, 2018: 1531 ).

However, any model created to study political participation in one country, need to be adapted to use in another one. In the process of customisation, factors that influence political participation in a particular political system of "authority-society" interaction should be taken into consideration. For example, T. Xue and J. van Stekelenburg offer a model of interaction between the Chinese authorities and society in the era of the development of digital technologies based on adaptation of relevant studies from both China and abroad to make a systematic analysis of the demand, supply and mobilisation of Chinese online activism (Xue, van Stekelenburg, 2018: 920)

In the transformation of the Russian political system, the following contradictions appear(1) a lack of balance between the state's responsiveness and preservation of the social order; a high level of tension between the new forms of political participation with the existing demands - an expansion of "structures of political possibilities" as conditions of democratisation of the political system; (2) tendencies to increase the number of the participation culture holders of with considerable differentiation of "the structure of political possibilities" in the Russian regions; (3) modification of the complex character of conflict interactions in the system "power society" under the influence of nonconventional forms of civil participation strengthening tension with conventional forms.

The focus of the research was suggested by hypothesis. The parameters of the political participation model dominating in a region are determined by the political context in which they appear and develop by the social context reflecting the quality of life in the region of the Russian Federation. The different strategies of political participation are used by social groups, which have various interests and possess different recourses. Besides, the increased number of individual models of political behaviour creates specific synergetic effects. 
That is why the general focus and results of citizens' involvement in political processes in many ways depend upon the structure and relative influence of the main types of social actors. The investigation of their concrete characteristics becomes the most important. The methodology is discussed in the following section.

\section{Methodology}

An expert survey determined the interrelation of the priority-oriented models of civic participation and the peculiarities of the political space of the Russian regions. The procedure of the survey presupposed the following actions: pointing out the essence of the problem in question and motives of addressing to the particular individual as a specialist; data verifying the expert's competence such as field of knowledge, experience in this field, qualification; information on the content of the questions; formation of each problem question; estimation of confidence in the expert's conclusion (opinion); additional remarks, commentaries, suggestions.

The political participation as a theoretical object of the research is determined as a complex action by which the citizens influence the function of the political system articulating their interests.

The representatives of the political, economic and socio-cultural segments of the elite community in the Central Federal District (CFD) served as an empirical object. The sample population included 90 persons. This number of experts is necessary and sufficient for securing the validation of the results of the research. The sample collection is constructed with the help of the procedure of phase-by-phase selection of polling objects. The selection units of the first phase (the primary units) are the types of regions in the CFD singled out on the basis of the quality of life evaluated according to the Federal Service of RF State Statistics for 2011. They are - leading regions (Belgorod region, Moscow region, the city of Moscow), medium regions (Bryansk region, Vladimir region, Voronezh region, Lipetsk region, Orel region, Ivanovo region, Ryazan region, Yaroslavl region), regions of catching-up development (Kostroma region, Tambov region, Tver region, Tula region). 30 experts were interviewed in each type of the CFD regions. The probability sampling method was used at the second stage. The secondary sampling units are segments of the regional elite (political, economic and sociocultural) with ten representatives from each segment. The hierarchy of the internal structure determined the selection at the third stage. Thus, within the economic elite, the study of the opinions of the representatives belonging to high-income, middle-income and low-income groups was held. The political elite is structuredin accordance with its association with the leading political institutions (legislative power, executive power, judicial power, political parties and constitutional institutions).

The differentiation of the socio-cultural elite is based on the nature of the activity. The primary criterion of the selection at the fourth level is an affiliation with the managerial personnel.

Given the closeness of the elite the observation units are selected with the help of the "snowball sampling" method. This method is a variety of a targeted selection in which it is assumed that the selection of additional (subsequent) respondents is made after they are referred to by the initially selected respondents. In the expert survey, the political context is defined as a factor of the development of civic participation of the population living the CFD.

The following indicators of "political space" were singled out: "parameters of the political system", "stability of the elite groups", "consolidation of the elite groups within the system", "political competence" (McAdam et al, 2004; Koopmans, 1995; Della Porta, 1999; Brady, 1999; Dalton, 2009; Ekman and Amnå, 2009; Macedo, 2005; Scharpf, 2000; Warren, 2011; Stoker, 2006). In accordance with these indicators, the survey was worked out.

The data evaluation research was conducted in three stages. During the first stage, methods of descriptive statistics, calculations of average tendencies, qualitative apprehension of group 
data was used. During the next two stages, methods of reference scales aggregation, a logical combination of particular characteristics, index computation, empiric and theoretical classification were employed, multidimensional tables were built, calculation of correlations was made, graphic interpretation of data was carries out. The following section discusses the results of the research.

\section{Results}

The reproduction of the system characteristics of the political process was found by measuring the degree of flexibility and the character of the risk liability of the administrative systems in the selected regions of the CFD. In general, the opinion of the elite community on this issue is characterised by ambiguity: on the semantic differential scales such as "reliability - risk liability", "stability - variability", "openness closeness" the median value dominates with some tendency to the left pole "reliability, stability, openness" (median value was 3 , mode was 2). With the relative univocacy of the estimation of the type of the regulation of economic relations is viewed as marketoriented (the median value and mode coincide $=2$ ).

The quality of life in the region determines the direction and intensity of the expert values of the political system in criterions of "reliability/riskogenics", "stability/variability" and "market-oriented economy/planned economy". With the decrease in the quality of life in the region, the median value tends to the pole "risk liability (riskogenics)", "variation", "focus on a planned economy".

Identifying the level of the "openness/ closeness" of the regional management system, the authors encountered with the problem of interpretations of the concept "openness", it is shown in the discrepancy of the estimation on the scales "openness - closeness" and "freedom of speech - censorship". For the most part, the above mentioned disparity is observed in the outsider regions, and it is caused by the fact that in September 2012, some of the regions in this group became the participants of the pilot project "Open Region" which presupposes a provision of Internet presence of the representatives of the local and regional elites. As a result, there is a substitution of concepts. "Openness" is interpreted as "presence/absence of individual websites of the state and municipal employees in social networks".

The results of the research show that the direction and the intensity of the expert estimations of the functional separation of the executive and legislative powers are characterised as neutral (indicators of the mode and the median coincide and were equal to 3 with the distribution of scale meanings from 1 to 5). The expert evaluations are largely determined by the possibilities provided by the administrative system in the region to save/improve a specific segment of the elite community. Thus, in the leading regions, the most optimistic estimations are given by the representatives of the political and economic elites, due to the favourable conditions to improve their status. In the medium regions, the political and socio-cultural segments demonstrate the loyal attitude to the existing distribution of the functional executive and legislative powers. The representatives of the socio-cultural segment of the outsider regions demonstrate a lower level of tolerance to the existing interrelationship between the executive and legislative authorities. The reserved estimation of the political and economic elite is connected with the ambiguity of the development prospects of these CFD regions and the least favourable conditions for self-realisation of the socio-cultural elite (Table $1)$.

\section{Choose the positions on the estimate scale that match the characteristics of the administration in your region}

The analysis of the variable "change of the composition of the authorities" enabled the authors to observe more clearly a tendency of the functional merge of the executive and legislative powers of the region (with an absolute dominance of the executive bodies) in the medium regions. Among the factors of 
renewal of the legislative authorities, the experts named the circumstances related to the functioning of the executive structures, in turn. Personnel changes in the executive authorities are determined by the formation of the representative institutions (Table 2 ).

Table 1: Functioning of the Executive and Legislative Authorities: Distribution in Accordance with the Elite Types in Different Regions

\begin{tabular}{|c|c|c|c|c|c|c|c|}
\hline \multirow{2}{*}{ Type of Region } & \multirow{4}{*}{ Type of Elite } & \multicolumn{4}{|c|}{ Estimate Scale from 1 to 5} \\
\cline { 2 - 6 } & & 1 & 2 & 3 & 4 & 5 \\
\hline \multirow{2}{*}{ Leading regions } & Political & 0 & 4 & 3 & 2 & 1 \\
\hline \multirow{3}{*}{ Medium Regions } & Economic & 0 & 4 & 3 & 1 & 2 \\
\cline { 2 - 6 } & Socio-Cultural & 0 & 4 & 1 & 1 & 3 \\
\cline { 2 - 6 } & Political & 2 & 3 & 3 & 1 & 1 \\
\hline \multirow{2}{*}{ Region of Catching-up Development } & Economic & 0 & 2 & 4 & 2 & 2 \\
\hline & Socio-Cultural & 3 & 2 & 3 & 1 & 1 \\
\hline & Political & 0 & 3 & 4 & 3 & 0 \\
\hline & Economic & 1 & 2 & 5 & 2 & 0 \\
\hline & Socio-Cultural & 1 & 1 & 3 & 3 & 1 \\
\hline
\end{tabular}

*We used semantic differential where 1 and $\mathbf{5}$ are polar characteristics and $\mathbf{3}$ is neutral

Source: Compiled by the authors on the basis of the expert survey A Model of the Political Participation as an Integrative Indicator of Structures of Political Opportunities of the Regions (by the example of the Russian Federation) (Agreement №14.B37.21.1018 from 07.09.2012. Under the auspices of the Federal Program Scientific and Scientific-Pedagogical Personnel of Innovative Russia for 2009-2013)

The elite groups in the leading regions rate the current system of government is estimated by as more responsive by their higher sensitivity to both institutional and non-institutional forms of influence on the system. In general, the experts' opinion in Belgorod and Moscow regions, the city of Moscow on these issues is characterised by a greater intensity, indicating a high level of the position consolidation. The decrease in the regional quality of life is associated with the citizens' political exclusion, which is reflected in the respondents' responses: the citizens' electoral participation is recognised as the only legal way to renew the authority. Legitimating the power in other forms is not considered as a mandatory condition of preserving the power positions.

\section{What do you associate a renewal of the staff composition of regional authorities with? (The choice of options is not limited)}

The sensitivity of the administrative system of the leading regions to the internal and external factors contributes to the preservation of a stable composition of the government. The elite subjects of this region in response to the question regarding the frequency of the renewal of the basic composition of the regional legislative and executive authorities gave preference to indicators " $3-5$ years" (15 experts) and "6 years" (15 and 14 experts, respectively). As a result, this sensitivity contributes to the reproduction of the system characteristics. In the medium regions and the regions of catching-up development, an interval between the changes of the elites is also "3-5 years." However, the number of the respondents who believed that a personnel rotation in the executive branch occurs more often (1-2 years) was found mainly by the political elite, and this finding confirms the conclusion above about the high degree of closeness of the administrative system in the regions of this type.

The political systems differ according to the level of responsiveness, and they are focused on a single method of recruiting the elite, that is, a system of guilds. 


\begin{tabular}{|c|c|c|c|c|c|c|}
\hline & \multicolumn{3}{|c|}{$\begin{array}{l}\text { Legislative } \\
\text { Authorities }\end{array}$} & \multicolumn{3}{|c|}{$\begin{array}{l}\text { Executive } \\
\text { Authorities }\end{array}$} \\
\hline & $\begin{array}{l}\frac{n}{0} \\
\frac{\pi}{\pi} \\
\stackrel{\Xi}{\unlhd}\end{array}$ & $\begin{array}{l}\frac{\varepsilon}{\partial} \\
\frac{\partial}{\partial} \\
\sum\end{array}$ & 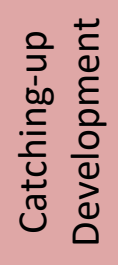 & $\begin{array}{l}\frac{n}{0} \\
\frac{\pi}{\pi} \\
\stackrel{\Xi}{\Xi}\end{array}$ & $\begin{array}{l}\frac{g}{3} \\
\frac{\partial}{d} \\
\sum\end{array}$ & 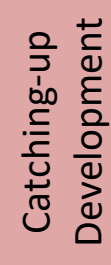 \\
\hline Change of the head of the region & 7 & 13 & 11 & 28 & 22 & 24 \\
\hline Electoral cycle & 20 & 18 & 18 & 4 & 9 & 5 \\
\hline Change of the economic situation in the region & 12 & 9 & 2 & 17 & 11 & 12 \\
\hline $\begin{array}{c}\text { Change of the composition of the federal } \\
\text { government }\end{array}$ & 4 & 11 & 9 & 18 & 15 & 9 \\
\hline $\begin{array}{c}\text { Change of the alignment of political forces in } \\
\text { the region }\end{array}$ & 19 & 8 & 13 & 18 & 11 & 13 \\
\hline $\begin{array}{l}\text { Reduction of the level of confidence to the } \\
\text { representatives of power structures }\end{array}$ & 14 & 12 & 4 & 18 & 9 & 6 \\
\hline $\begin{array}{l}\text { Disclosure of the facts of corruption in the } \\
\text { regional government }\end{array}$ & 16 & 10 & 6 & 19 & 14 & 20 \\
\hline Growth of protest in the region & 16 & 8 & 5 & 15 & 8 & 3 \\
\hline Other & 1 & 2 & 0 & 2 & 1 & 1 \\
\hline
\end{tabular}

Source: Compiled by the authors on the basis of the expert survey A Model of the Political Participation as an Integrative Indicator of Structures of Political Opportunities of the Regions (by the example of the Russian Federation) (Agreement №14.B37.21.1018 from 07.09.2012. Under the auspices of the Federal Program Scientific and Scientific-Pedagogical Personnel of Innovative Russia for 2009-2013)

The complete package of features, including an ideological component, is inherent in the executive bodies of the medium regions and the regions of catching-up development with a higher intensity of the latter (Table 3).

In your opinion, what are the reasons of the selection of candidates to the executive authorities? (Choose no more than three answers)

The evaluation of the tendencies of the development of the elite groups demonstrates a demand for authoritarianism. The following basic features of the political elite in a mediumterm perspective were mentioned: clannishness (49.2\%), loyalty to a superior (43.1

\%). This last feature does not have a territorial location.

This finding is demonstrated by the analysis of the variable "interdependence of institutional $n$ non-institutional subjects". The results of the research show that the potential to influence the administrative system is determined by the degree of the subjects' institutionalisation, their attitude to the existing regime and the level of legitimacy. The major factors which determine the role in the process of making political decisions are the existence of informal links with the representatives of the government authorities and possession of certain recourses (financial, information, administrative). 
Table 3: Basic Reasons of the Selection of the Candidates to the Executive Authorities: Distribution by the Type of the Region

\begin{tabular}{|c|c|c|c|}
\hline & $\begin{array}{l}\text { Leading } \\
\text { Regions }\end{array}$ & $\begin{array}{l}\text { Medium } \\
\text { Regions }\end{array}$ & $\begin{array}{l}\text { Regions of Catching-up } \\
\text { Development }\end{array}$ \\
\hline $\begin{array}{l}\text { Private and non-competitive nature of } \\
\text { the selection of representatives }\end{array}$ & 9 & 16 & 9 \\
\hline $\begin{array}{l}\text { Narrow circle of people who define } \\
\text { the composition of the political elite }\end{array}$ & 20 & 11 & 13 \\
\hline $\begin{array}{l}\text { Limited range of social and political } \\
\text { groups in which the selection took part }\end{array}$ & 7 & 11 & 13 \\
\hline $\begin{array}{l}\text { Loyalty to a superior as a basic } \\
\text { condition for inclusion in the elite } \\
\text { groups }\end{array}$ & 6 & 11 & 12 \\
\hline $\begin{array}{l}\text { Recommendations of the party bodies } \\
\text { in selecting contenders. }\end{array}$ & 14 & 7 & 8 \\
\hline $\begin{array}{l}\text { Commitment to the official } \\
\text { ideology as a necessary condition for } \\
\text { inclusion in the elite. }\end{array}$ & 6 & 7 & 12 \\
\hline \multicolumn{4}{|c|}{$\begin{array}{l}\text { Source: Compiled by the authors on the basis of the expert survey A Model of the Politica } \\
\text { Participation as an Integrative Indicator of Structures of Political Opportunities of the Regions (by } \\
\text { the example of the Russian Federation) (Agreement №14.B37.21.1018 from 07.09.2012. Under } \\
\text { the auspices of the Federal Program Scientific and Scientific-Pedagogical Personnel of Innovative } \\
\text { Russia for 2009-2013) }\end{array}$} \\
\hline
\end{tabular}

The expert society named the following significant participants of the political process: stable political and economic groups (clans) $(\mathrm{Mo}=5)$, parliamentary parties $(\mathrm{Mo}=5)$, business structures (there are two modes: $M o=4 n$ $\mathrm{Mo}=5)$, security $(\mathrm{Mo}=4)$, mass media $(\mathrm{Mo}=4)$. The businesses have the greatest potential influence (the average rating 3.83 points out of 5). Non-parliamentary political parties, youth pro-governmental movements, women's progovernmental movements, ecological movements, the church, volunteer movements, protest movements, trade unions are not recognised as significant political actors $(\mathrm{Mo}=1$, where 1 - does not influence the decisionmaking process). Among the abovementioned entities, non-parliamentary parties are found having the least potential to influence. This finding enabled the corporate authors put forward a hypothesis about the deformation of political parties as an institution since they carry out functions limited by the parliamentary activity. Thus, liberalisation of the party system will promote neither its strengthening nor political mobilisation of the citizens.

The most intense negativity on this question was expressed by the experts from the regions of catching-up development. The uttermost scepticism is demonstrated in connection with a politically subjective nature of ecological, volunteer, trade union movements, youth and women's pro-governmental organisations.

The leading regions in their turn are distinguished by an exaggerated estimate of the lobbyist capacity of the Civic Chamber of the Russian Federation and the same time disappointment in protest movement in the role of the Church.

The following fact is worth considering: among non-institutional subjects, the primary representation belongs to the initiative groups of the citizens (informal entities of citizens) (the average estimate is 2.73 points). At the same time, the expert society rates the activity of the citizens' participation in this form as rather high. Among possible forms of participation in 
the political life of the country, establishing initiative groups the aim of which is to solve local problems (householders' society, "hoodwinked investors", etc.) takes the 4th place. The territorial distribution enabled the researchers to single out a considerable difference. If in the medium regions and the regions of catching-up development this form is considered to be more preferable for the political involvement than in the leading regions where it is considered to be a realisable one.

The model of political participation determines not only the stability of the elite groups, but also the reasons for their consolidation, and above all the values. The structure of the value system of the elite groups in the CFD was studied by creating a hierarchy. In accordance with the approach introduced by N.I. Lapina, the structural layers of the value hierarchy were differentiated on account of their functions: universal and integrating (nuclear), socio-cultural and integrating (reserve), sociocultural and differentiating (differential) and conflict regulating (periphery). The distribution of the values by the layers is shown in Table 4.

\begin{tabular}{|c|c|}
\hline Structural layers & Percentage \\
\hline \multirow{12}{*}{$\begin{array}{l}\text { Integrating nucleus } \\
\text { (over 57\%) }\end{array}$} & Family (91.1) \\
\hline & Health (90.0) \\
\hline & Security (67.8) \\
\hline & Conscience (72.2) \\
\hline & Freedom (66.7) \\
\hline & Dignity (64.4) \\
\hline & Justice (64.4) \\
\hline & Peace (63.3) \\
\hline & Labour (62.2) \\
\hline & Law (62.2) \\
\hline & Stability (61.1) \\
\hline & Human Rights (57.8) \\
\hline \multirow{6}{*}{$\begin{array}{l}\text { Integrating reserve } \\
(45.0 \%-56.9 \%)\end{array}$} & $\operatorname{Order}(56.7)$ \\
\hline & Prosperity (55.6) \\
\hline & Success (50.0) \\
\hline & Property (48.9) \\
\hline & Spirituality (48.9) \\
\hline & Patriotism (46.7) \\
\hline \multirow{3}{*}{$\begin{array}{l}\text { Opposing differential } \\
(30.0 \%-44.9 \%)\end{array}$} & Defense (42.2) \\
\hline & Democracy (41.1) \\
\hline & Religion (30.0) \\
\hline \multirow{5}{*}{$\begin{array}{l}\text { Conflictogenic periphery (less than } \\
\qquad 30.0 \%)\end{array}$} & Solidarity (27.8) \\
\hline & Tolerance (27.8) \\
\hline & State (24.4) \\
\hline & Power (18.9) \\
\hline & Firmness (17.7) \\
\hline \multicolumn{2}{|c|}{$\begin{array}{l}\text { Source: Compiled by the authors on the basis of the expert survey A Model of the Political } \\
\text { Participation as an Integrative Indicator of Structures of Political Opportunities of the Regions (by } \\
\text { the example of the Russian Federation) (Agreement №14.B37.21.1018 from 07.09.2012. Under } \\
\text { the auspices of the Federal Program Scientific and Scientific-Pedagogical Personnel of the } \\
\text { Innovative Russia for 2009-2013) }\end{array}$} \\
\hline
\end{tabular}


What do you consider to be valuable in life in the following list of values (the choice is not limited), in \%.

The analysis of the hierarchal structure of the value system of the elite group enabled the researchers to come to a conclusion about the consolidation of the society because the number of the values belonging to the integrating nucleus reaches $50 \%$ of the complete list. Thereby less than one third is taken up by the opposing differential and conflictogenic periphery.

Besides the following contingency of two indexes was singled out: the quality of life in the region and the level of the consolidation of the elite. The values composing the integrating nucleus and integrating reserve, their number differ dramatically in the regions of the CFD. If in the leading regions, the integrating nucleus is composed of 16 values (both traditional and modern), but such values as "democracy", "property" and "solidarity" are included into an integrating reserve, but in the regions of catching-up development, only four values composed an integrating layer (all of them are traditional), and the values significant from the point of view of the participation culture refer to the conflictogenic periphery. This finding confirms the above-concluded establishing the authoritarian tendencies in the regions of catching-up development. Expanding a differentiating layer gives evidence of the high internal conflictogenic potential of the elite group in the CFD regions with low living standards.

This tendency is reflected in the analysis of the variable "conflictogenics of the relationship within the elite". Despite the fact that the experts in the leading regions claim that the competition is the main means of cooperation between the representatives of the political elite in the CFD regions, the clear definition of the object of the conflict (determination to redistribute the resources and corruptive practices) with the high level of intensity of statements testifies the open phase of conflict interaction. It provides more opportunities for regulation and as a consequence for the decrease of the level of social tension in this region. The nature of the inter-elite communications in the medium regions indicates a merge of the political space and the space of everyday practices which is proved by an emphasis on such behaviour strategies as cooperation and conflict avoidance. A contradiction characterises this situation: on the one hand, local initiatives expand the political practices, on the other hand, they limit the political subjectivity of citizens and promote paternalism.

The blur of the opinions of the representatives of the elite society in the regions of catching-up development is reflected in ambiguity in defining both the principals of interrelations of the elite groups of the political sphere and the object of disagreement. This fact testifies to the domination of conflicts in the latent phase, and it is a consequence of the manifestation of authoritarian tendencies in the CFD regions of this type and leads to increasing social tension.

The nature of the conflict determines the level of political tolerance within the elites. The effective adjustment of contradictions in the leading regions correlates with the low level of demonstration of hostility to the political opponents including extremist oriented (according to the aims/ methods of activity) oppositional groups (Left Front -8 experts, National Bolshevik Party -8 experts, Social Democratic Movement "Solidarity" - 9 experts). On the contrary, the high level of the intergroup tension is reflected in the ranking of the direction and intensity of the confronting political powers (Left Front - 11 experts, National Bolshevik Party - 15 experts, Social Democratic Movement "Solidarity" - 10 experts). The spectre of negatively perceived subjects was increased on account of the system opposition in the name of CPRF (Communist Party of the Russian Federation). Interestingly, irrespective of the type of a region the representatives of the elites do not mention the political party "United Russia". It supports their opinion that the power party membership is viewed as a basic criterion of elite recruitment. The names of the protest 
movements' leaders are significant for the rating of the given political powers. The absence of the leaders' names in the survey decreases the intensity of the demonstrated disaffection.

The following indicators were chosen to define the level of political tolerance: the possibility for political opponents to participate in election processes at various levels, the right to use information resources, involvement in the process of making and carrying out political decisions. The analysis of the sociological research showed that the elite communities allow the political opponents to realise their passive suffrage during the formation of legislative assemblies (index of tolerance It1 $=14,4)$ and freedom of speech ( $\mid t 2=9,7)$. Passive suffrage limits the possibility of participation in forming a personnel group among the executive authorities (It3=-3), in making and carrying out political decisions (It4=-35,5), and in control over mass-media $(\mathrm{tt} 5=-50,8)$. The difference in the tolerance indexes relating to a type of executive and legislature authorities in many respects caused by the domination of the first branch over the second one and that allows specifying the different features of the political systems in the CFD regions.

The cross-sectional analysis of the variables measuring the attitude of the political elite towards their political opponents according to the indicator "type of the region» allowed the authors to confirm the conclusions which had been drawn (Table 5). The divergences in estimations of the opponents' political rights are defined, firstly, by a level of differentiation of functions of the executive and legislature authorities; secondly, by a correlation of declared and realised valuables; and thirdly, by regime characteristics of the regional political systems. Thus, the presence of such features as a higher level of responsiveness, a democratic orientation, value consolidation which are typical for the leading region, stipulate loyalty to various political forces according to a considerable number of indicators. Against the background of increased citizens' paternalism, there is an intolerance of the elites in the medium regions to the representatives of the non-system opposition, whose main feature is a confrontation with the state policy. As a result, the latter was practically refused to display their political activity. The combination of loyalty with a realisation of the professional political activity and a restriction of the activity in the field of the political mobilisation of citizens is a distinctive feature in the perception of the political opponents in the regions of catching-up development. Such a different situation can be explained, firstly, by definition given by the elite to the political culture of mass groups as subordinate/ patriarchal; secondly, by a recognition of the authoritative character of the mobilisation, dominated by the state structures; thirdly, by a high belief in manipulative possibilities of mass media.

Comparing such variables as "assessment of the qualities of the former political elite" and "assessment of the qualities of the new elite" showed that in the minds of the elite community there were various images of the political elite of the end of $X X$ and the beginning of $\mathrm{XXI}$ centuries. The following features were defined as basic features of the "old elite": personal links/connections (71.9\%), careerism (47.2\%) and experience (40.4\%). "The new elite", although preserving some features (connections/links) (75.9\%), a careerism $(74.7 \%)$ ) is considered innovative in a greater degree. New features such as competence $(40.2 \%)$, ability to make a compromise $(43.7 \%)$ appear in the ranking. There is an intensity of the expert community's opinions concerning an elites' image at the beginning of XXI century with a considerable differentiation by the "region type" criterion (Table 6). 
Table 5: Index Profile of Political Tolerance of the Elites of the CFD Regions

\begin{tabular}{|c|c|c|c|}
\hline & Leading Regions & Medium Regions & Regions of Catching-up Development \\
\hline $\begin{array}{l}\text { Participate in the } \\
\text { elections to } \\
\text { legislative assemblies }\end{array}$ & 9 & -8 & 6 \\
\hline $\begin{array}{l}\text { Participate in the } \\
\text { elections of the Head } \\
\text { of the State }\end{array}$ & 3 & -9 & 4 \\
\hline $\begin{array}{l}\text { Participate in the } \\
\text { elections of the head } \\
\text { of the region }\end{array}$ & 5 & -7 & 2 \\
\hline $\begin{array}{l}\text { Popularise your own } \\
\text { politics }\end{array}$ & 5 & 1 & 0 \\
\hline $\begin{array}{l}\text { Organise and carry } \\
\text { out mass events/ } \\
\text { actions }\end{array}$ & 5 & -5 & 0 \\
\hline Controlmassmedia & 2 & -13 & -16 \\
\hline $\begin{array}{l}\text { Participate in } \\
\text { developing and } \\
\text { making political } \\
\text { decisions }\end{array}$ & 1 & -13 & 10 \\
\hline $\begin{array}{l}\text { Control the execution } \\
\text { of the state programs }\end{array}$ & 5 & -14 & 2 \\
\hline
\end{tabular}

Source: Compiled by the authors on the basis of the expert survey A Model of the Political Participation as an Integrative Indicator of Structures of Political Opportunities of the Regions (by the example of the Russian Federation) (Agreement №14.B37.21.1018 from 07.09.2012. Under the auspices of the Federal Program Scientific and Scientific-Pedagogical Personnel of the Innovative Russia for 2009-2013)

In your opinion, what is typical for the representatives of the management sphere at the end of the $X X$ century and the beginning of the XXI century in the sphere?

The graphic analysis of the data allowed the authors to come to the conclusions about an innovative trend of the political elite transformation in the leading regions and a relative traditionalism of the elite community in the medium regions and the regions of catching-up development. An ability to bear responsibility (one of the system-forming characteristics of the elite as a social group) was mentioned only by the experts in the CFD subjects with a high quality of life. In the regions of the same type, there is a generally high level of continuity with an increased intensity of the estimations of the dominating qualities.
The description of the structure of the political possibilities presupposes an analysis of the political competence of the mass groups' representatives. The study of the cognitive component allowed the authors to conclude the high intensity and the positive orientation of the experts' estimations, in connection with the level of the citizens' political knowledge. So, in the CFD, the information awareness index on the average is 55.6. There is a differentiation of the elite's opinions by the type of a region: the better the quality of life in the region is, the higher is the information awareness index. At the same time, the experts' position on a degree of the citizens' interest in politics is not so unequivocal: half of the respondents indicate their interest as average, one third (due to the representatives of the regions of catching-up development and the medium regions) as insignificant, limiting their interest 
to receiving the political information and experts noted the sporadic character of the participating in voting. Besides, $30.3 \%$ of political activity.

\begin{tabular}{|c|c|c|c|c|c|c|}
\hline \multicolumn{7}{|c|}{$\begin{array}{l}\text { Table 6: The Correlation of the Elite Images at the End of XX century - The Beginning of XXI } \\
\text { Century- Distribution by the Types of the Region }\end{array}$} \\
\hline & \multicolumn{2}{|c|}{ Leading Regions } & \multicolumn{2}{|c|}{ Medium Regions } & \multicolumn{2}{|c|}{ Regions of Catching-up Development } \\
\hline & 흥 & 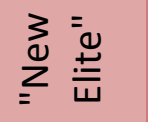 & 흥 & 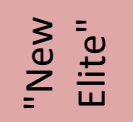 & 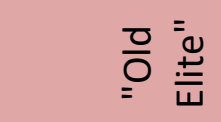 & 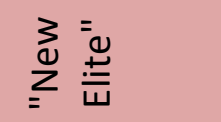 \\
\hline Competence & 13 & 14 & 6 & 11 & 9 & 10 \\
\hline $\begin{array}{c}\text { Personal } \\
\text { Connections }\end{array}$ & 20 & 22 & 22 & 21 & 22 & 23 \\
\hline $\begin{array}{l}\text { Ability to bring } \\
\text { responsibility }\end{array}$ & 16 & 19 & 5 & 8 & 5 & 6 \\
\hline $\begin{array}{l}\text { Ability to make } \\
\text { non-standard } \\
\text { decisions }\end{array}$ & 9 & 16 & 8 & 8 & 6 & 9 \\
\hline Legality & 13 & 17 & 5 & 5 & 6 & 7 \\
\hline $\begin{array}{l}\text { Ability to make } \\
\text { compromises }\end{array}$ & 12 & 18 & 9 & 12 & 7 & 8 \\
\hline Careerism & 16 & 24 & 12 & 21 & 14 & 20 \\
\hline $\begin{array}{c}\text { Observance of } \\
\text { moral-ethical } \\
\text { standards }\end{array}$ & 2 & 12 & 6 & 3 & 4 & 4 \\
\hline Experience & 12 & 18 & 13 & 6 & 11 & 8 \\
\hline \multicolumn{7}{|c|}{$\begin{array}{l}\text { Source: Compiled by the authors on the basis of the expert survey A Model of the Political } \\
\text { Participation as an Integrative Indicator of Structures of Political Opportunities of the Regions (by } \\
\text { the example of the Russian Federation) (Agreement №14.B37.21.1018 from 07.09.2012. Under } \\
\text { the auspices of the Federal Program Scientific and Scientific-Pedagogical Personnel of the } \\
\text { Innovative Russia for 2009-2013) }\end{array}$} \\
\hline
\end{tabular}

Estimating the comprehensible forms of the political participation, the experts in the medium regions specified a rather long list of variants of mainly conventional activity; while in the leading regions and the regions of catching-up development this list is limited and reduced. In the leading regions, it is limited to two non-electoral forms which differ according to a degree of loyalty ("refusal to pay housing and communal bills" and "participation in signing collective letters to the authorities"). In the regions of catching-up development, it is limited to three forms with obvious domination of the electoral form. However, according to the experts, there is a discrepancy between the effective and strong-willed constituents of the citizens' political competence. This discrepancy is reflected in a divergence of comprehensible and demanded forms of participation. Thus, in the leading regions (at a high level of the opinions' intensity) the following forms were mentioned among the realised forms: participation in the authorised demonstrations, "people's festivals" and a creation of initiative groups with the aim to solve local problems. In the medial regions (with a decrease of intensity in relation to both leaders and to the preferable forms), a participation in "people's festivals" and a creation of initiative groups with the aim to solve local problems. In the regions of catching-up development, all the forms are reduced to only one - participation in 
"people's festivals", and this form has no political context.

The elite community positively estimates the productivity of the citizens' political participation. The cumulative index of influence (I=94.1) demonstrates it. In this regard, the influence indexes are the highest in cases of an estimation of the influence potential on the activity of the executive powers at the regional and local levels (the indicators vary from 28.9 to 36). Similar tendencies appear at the level of separate regions. However, a differentiation in the intensity of expert estimations depending on the quality of life in a region is observed. Thus, in the leading regions, there is a general agreement on the high degree of openness of the executive power (in the name of governors, heads of the municipal administrations), and the closed nature of the legislative power. In the medium regions and the regions of catching-up development, the respondents' opinions are not marked with a high level of intensity, and it testifies to the scepticism of the experts in the context of the political subjectivity of the citizens united in the groups (Table 7).

As a consequence, in these regions, the expert community named the reached motives of the political participation more seldom than in the leading regions. At the same time, the experts' estimations of the avoidance motives in the regions of catching-up development are characterised by a higher level of intensity. 9 out of 9 respondents pointed out that the main reason for unwillingness to participate in the political process is the ineffectiveness of the activity. In the leading regions, the following motives dominate achievement of the results ("a desire to participate in solving the existing problems") and an avoidance of sanctions ("political participation as a civic duty").

\section{Table 7: Evaluation of the Potential of the Citizens' Influence}

\begin{tabular}{|c|c|c|c|}
\hline & $\begin{array}{c}\text { Leading } \\
\text { Regions }\end{array}$ & $\begin{array}{c}\text { Medium } \\
\text { Regions }\end{array}$ & $\begin{array}{c}\text { Regions of Catching-up } \\
\text { Development }\end{array}$ \\
\hline $\begin{array}{c}\text { Governor } \\
\text { Oblast (Regional) Duma }\end{array}$ & 16 & 7 & 9 \\
\hline $\begin{array}{c}\text { Head (mayor) of the } \\
\text { city }\end{array}$ & -11 & 6 & 2 \\
\hline City Authorities & 16 & 9 & 1 \\
\hline City Duma & -7 & 8 & 5 \\
\hline
\end{tabular}

Source: Compiled by the authors on the basis of the expert survey A Model of the Political Participation as an Integrative Indicator of Structures of Political Opportunities of the Regions (by the example of the Russian Federation) (Agreement №14.B37.21.1018 from 07.09.2012. Under the auspices of the Federal Program Scientific and Scientific-Pedagogical Personnel of the Innovative Russia for 2009-2013)

In your opinion, do the citizens of the region have an opportunity to influence the decisionmaking process in the regional and municipal authorities?

The answer to this questionwas confirmed by the analysis of the variable "level of reciprocity". $65.9 \%$ of the survey participants recognise the citizens' personal responsibility for the events which occur in the country. That is, they estimate the political subjectivity, the level of which is connected with the quality of life in the community: the higher subsistence in the region, the greater is the power resource of the citizens (the responsibility index in the leading regions is $I_{01}=13$, in the medium regions is $I_{02}=9$, in the regions of catching-up development is $\mathrm{I}_{03}=6$ ). In addition, considerable disproportions in the system of the relationship "power - society" were caused by a discrepancy between low estimations of the functions of the state institutions and overestimated expectations in relation to the citizens (the index of functionality is $I_{f}=-4.8$ ). The finding is mainly relevant to the leading regions. In experts' opinion, charitable organisations are considered to be the most 
optimal structure of the support for the destitute (21 out of 30). While in other types of CFD regions the appeals to the state on principles of address support have more unequivocal character (23 and 17 out of 30 for the regions of catching-up development and medium regions accordingly). In this regard the analysis of the variable "level of confidence in social and political institutions" again allowed the authors to track the domination of executive power. Among the most legitimate structures regardless the type of the region, the President of the Russian Federation (64\%), the governor of the region (39.3\%) and massmedia (30.3\%) are named. It is necessary to notice that in regions with an average and low quality of life the church enjoys considerable confidence $(43.3 \%$ and $33.3 \%$ of the respondents in medium regions and the regions of catching-up development accordingly, and $20.0 \%$ - in the leading regions), and it gives evidence to manifestation of traditionalism of the regions in question.

\section{Discussion}

The research identified the following parameters of the political space in the CFD regions: a transition from mixed (half-opened) types of the elites' recruitment to the closed ones; a regional stagnation of the elite which grows as the quality of life decreases in the CFD regions; a reduction of the inter elite circulation in conditions of a conflict model of the interaction of the elites; and the preservation of the inter elite circulation in conditions of a partner model; an appearance of ideocratic evolution factors of the selection in the medium regions and the regions of catching-up development; a domination of the informal channels of forming the elite community, where an administrative and political advancement is achieved not by personal qualities, but because of one's membership in one of the groups of influence. It leads to the creation of target clans and groups which participate in the distribution of "power clan" among themselves and directly influence a decision-making process. These parameters allowed the authors to reveal the dynamic tendencies of the structure of the political possibilities. The above mentioned tendencies considerably limit the variability of the political participation models, narrowing the forms of political activity to the electoral one.

The typology of the civil subjectivity was offered. This typologisationwas based on a system of the following integrative indicators which are defined by the operationalisation procedure of the category "political competence": external and internal productivity, an instrumentalisation. The following types were singled out: innovative, reformist, stabilising, conformist-adaptive, indifferent-apathetic, and maladjustedaggressive. The survey found the fact that the dominating segment of the subjectivity carriers is connected with the quality of life in a region. In the leading regions, the model of political participation is determined by the reformist and stabilising types, with some emphasis on the latter; in the medium regions - by the indifferent-apathetic and maladjustedaggressive type with a domination of the first type; in the regions of catching-up development, all the types are present evenly with an insignificant domination of the indifferent-apathetic type.

\section{Conclusion}

On the assumption of the conditions and tendencies of the development of the structure of the political possibilities and the characteristics of the dominating segment of the civil subjectivity carrier, a perspective model of the political participation for each type of the regions was defined. This model allows the authors to formulate recommendations on the on-going development of political competence by the parameters of constructive participation.

The suggested methodology and the research methods may be used in the monitoring, and as a consequence, may serve as a basis for correcting the realisation of the decisions taken (in accordance with an incremental model) and in whole for increasing efficiency of the process of making political decisions, promoting recourses saving, creating conditions for the 
use of benchmarking technologies in the regional authorities. The suggested recommendations are oriented on a long-term perspective.

The political authorities may use the materials of the research in their work, which is connected with expanding the interrelationships and forming partnerships with the citizens at the various levels of the political infrastructure.

The political parties may use the results of the typology of the political subjectivity of the population in the regions of Russia for the optimal implementation of their ideological, socialisation and mobilisation functions, as well as for the creation of a constructive dialogue between different participants of the political process.

\section{References}

Brady, H. (1999). Political Participation: Measures of Political Attitudes. Wrightsman. San Diego: Academic Press.

Dalton, R. (2009). The Good Citizen: How A Younger Generation Is Reshaping American Politics. Revised Edition. Washington, DC: CQ Press.

Della Porta, D. and Diani, M. (1999). Social Movements: An Introduction. Oxford: Basil Blackwell.

Ekman, J. and Amnå, E. (2009). Political Participation and Civic Engagement: Towards $A$ New Typology. Youth \& Society (YeS). Working Paper. No. 2

Koopmans, R. (1995). Democracy from Below. New Social Movements and the Political System in West Germany. Boulder: Westview Press.

Lane, D.S. Dal Cin, S. V. (2018). Sharing beyond Slacktivism: the effect of socially observable prosocial media sharing on subsequent offline helping behavior. Information Communication and Society, Vol. 21, Issue 11: 1523-1540

Macedo, S. (2005). Democracy at Risk: How Political Choices Undermine Citizen

Participation, and What We Can Do About It. Washington, DC: Brookings Institution Press. McAdam, D., McCarthy, J.D., Zald, M.N. (2004). Comparative perspectives on social movements: political opportunities, mobilizing structures, and cultural framing. Cambridge: Cambridge University Press.

Scharpf, F. (2000).Institutions in Comparative Policy Research.Comparative Political Studies, Vol. 33: 783-784.

Stoker, G. (2006). Why Politics Matters: Making Democracy Work. Palgrave Macmillan.

Wang, T. and Shen, F. (2018). Perceived party polarization, news attentiveness, and political participation: a mediated moderation model. Asian Journal of Communication, Vol. 28, Issue 6: 620-637

Warren, M.E. (2011). Exit-based Empowerment in Democratic Theory. American Political Science Review, Vol. 105: 683-701.

Xue, T. and van Stekelenburg, J. (2018).When the Internet meets collective action: The traditional and creative ways of political participation in China.Current Sociology, Vol. 66, Issue 6: 911-928

\section{Acknowledgements}

The article is based on the analysis of the empirical data obtained from the expert survey titled A Model of the Political Participation as an Integrative Indicator of Structures of Political Opportunities of the Regions (by the example of the Russian Federation) (Agreement №14.B37.21.1018 from 07.09.2012. Under the auspices of the Federal Program Scientific and Scientific-Pedagogical Personnel of the Innovative Russia for 2009-2013). 